\title{
Glutamine Deprivation Enhances Acetyl-CoA Carboxylase Inhibitor-induced Death of Human Pancreatic Cancer Cells
}

\author{
KOJI NISHI ${ }^{1,2}$, MINA SUZUKI ${ }^{2}$, NORIKO YAMAMOTO ${ }^{2}$, AYAKO MATSUMOTO $^{2}$, YUMIKO IWASE ${ }^{2}$, \\ KEISHI YAMASAKI ${ }^{1,3}$, MASAKI OTAGIRI $^{1,3}$ and NAGAHIKO YUMITA ${ }^{2}$ \\ ${ }^{1}$ Faculty of Pharmaceutical Sciences, Sojo University, Kumamoto, Japan; \\ ${ }^{2}$ Laboratory of Drug Metabolism and Pharmacotherapeutics, Department of Clinical Pharmacy, \\ Yokohama University of Pharmacy, Yokohama, Japan; \\ ${ }^{3}$ DDS Research Institute, Sojo University, Kumamoto, Japan
}

\begin{abstract}
Background/Aim: Acetyl-CoA carboxylase (ACC) is a rate-limiting enzyme in fatty acid synthesis. In this study, we investigated the effect of ACC inhibition on survival of pancreatic cancer cells. Material and Methods: AsPC-1, BXPC-3 and PANC-1 were used as human pancreatic cancer cell lines. 5-(etradecyloxy)-2-furoic acid (TOFA) and bis-2(5-phenylacetamido-1,2,4-thiadiazol-2-yl) ethyl sulfide (BPTES) were used as inhibitors of ACC and glutaminase (GLS) respectively. Apoptotic and live cells were distinguished by annexin-V staining. The activity of caspase-3 was evaluated by measuring the fluorescence intensity of the degradation product of the substrate, N-acetyl-Asp-Glu-Val-Asp-7-amido-4trifluoromethylcoumarin. Results: TOFA increased the number of annexin V-positive cells and enhanced caspase-3 activity in AsPC-1 and BxPC-3, but not in PANC-1 cells. The number of PANC-1 cells increased after $48 \mathrm{~h}$ in Earle's balanced salt solution. Interestingly, proliferation of PANC-1 cells was drastically suppressed by glutamine deprivation, but not by inhibition of glycolysis. BPTES also induced cell death to the same extent as glutamine deprivation. In addition, TOFA induced cell death of PANC-1 cells, both in the presence of BPTES and with glutamine deprivation, suggesting that inhibition of glutaminolysis causes cell death and enhances the effect of TOFA in PANC-1 cells. Conclusion: These findings suggest that glutaminolysis is important for the survival of pancreatic cancer cells showing tolerance to nutrient starvation such as PANC-1 cells, and use of a combination of inhibitors of ACC and GLS may be a new strategy for treatment of pancreatic cancer.
\end{abstract}

Correspondence to: Koji Nishi, Ph.D., Faculty of Pharmaceutical Sciences, Sojo University, 4-22-1 Ikeda, Nishi-ku, Kumamoto 8600082, Japan. Tel: +81 963263543, Fax: +81 963265048, e-mail: knishi@ph.sojo-u.ac.jp

Key Words: Pancreatic cancer, PANC-1, glutamine, fatty acid, acetyl-CoA carboxylase.
Pancreatic cancer is the fourth and third leading cause of cancer-related deaths in Japan and the United States, respectively (1-3). Pancreatic cancer is one of the most lethal types of cancer, with a 5-year relative survival rate of less than $8 \%$ in Japan (3). Although standard chemotherapy regimens consisting of oxaliplatin, irinotecan, fluorouracil, and leucovorin (FOLFIRINOX); gemcitabine plus nabpaclitaxel; or gemcitabine plus erlotinib are widely used as first-line therapy to treat patients with advanced and metastatic pancreatic cancer, their antitumor effects (progression and survival rates) are remarkably lower than for other solid tumors (4-6).

Fatty acids are one of the most important substances involved in cell survival, proliferation, and metabolism. Several lipogenic enzymes such as fatty acid synthase (FAS) and acetyl-CoA carboxylase (ACC) contribute to production of fatty acids, which are required for the survival and proliferation of cancer cells $(7,8)$. In the first step of fatty acid synthesis, acetyl-CoA is carboxylated by ACC to form malonyl-CoA (9), and then elongated by FAS to form longchain fatty acids, mainly the 16-carbon fatty acid, palmitate (10, 11). Immunohistochemical studies have shown a markedly increased expression of FAS in many types of human epithelial cancer including of the breast, colorectum, prostate, bladder, ovary, esophagus, stomach, lung, oral tongue, oral cavity, head and neck, thyroid, and endometrium (7). ACC is also highly expressed in breast cancer cells (8). In addition, ATP citrate lyase, which produces acetyl-CoA from cytosol citrate, is also markedly increased in cancer cells (12-14). These observations suggest that these enzymes are essential to the survival of tumor cells and become a therapeutic target for pancreatic cancer. Previous studies reported that inhibition of FAS and ACC by chemical inhibitors or RNA interference-gene silencing suppresses proliferation and induces apoptosis of tumor cells, but not of non-malignant cells (15-20). Although this effect is thought to be due to the decrease in fatty acids, a controversial report 
showed that malonyl-CoA mediates cytotoxicity induced by FAS inhibition in breast and prostate cancer cells (21). Recently, we also reported that inhibition of ACC by 5(tetradecyloxy)-2-furoic acid (TOFA), a specific inhibitor of ACC, suppressed proliferation and induced apoptosis, and addition of palmitate suppressed apoptosis in pancreatic cancer cells (22). These results indicate that a decrease in fatty acids induces apoptosis in pancreatic cancer cells, but the exact mechanism has not been clarified.

PANC-1 cells are reported to be tolerant to starvation of nutrients such as glucose and amino acids (23). Maddocks et al. observed that pancreatic tumors in a v-Ki-ras2 Kirsten rat sarcoma viral oncogene homolog (KRAS)-driven mouse model were able to adapt to an environment with low nutrients (24). These findings imply that pancreatic cancer cells partly change their metabolic pattern to an unusual pattern for tolerance to nutrient starvation, and this property may be a reason for the poor effect of chemotherapy. Therefore, here we investigated and discussed the mechanism of tolerance to nutrient starvation of pancreatic cancer cells and the possibility of a new therapeutic strategy.

\section{Materials and Methods}

Cell cultures and reagents. The human pancreatic cancer cell lines, AsPC-1, BxPC-3, and PANC-1, were obtained from the American Type Culture Collection (Manassas, VA, USA). AsPC-1 and BxPC-3 cells were cultured in the recommended RPMI 1640 medium, and PANC-1 cells were cultured in Dulbecco's modified Eagle medium (DMEM). Both media were supplemented with $10 \%$ heat-inactivated fetal bovine serum (GIBCO, Invitrogen, Carlsbad, CA, USA), penicillin $100 \mathrm{U} / \mathrm{ml}$, and streptomycin $100 \mathrm{pg} / \mathrm{ml}$ (Sigma-Aldrich; Merck KGaA, Darmstadt, Germany) in $95 \%$ humidified air and $5 \%$ carbon dioxide at $37^{\circ} \mathrm{C}$. TOFA, Earle's balanced salt solution (EBSS), 2-deoxy-D-glucose, and bis-2-(5-phenylacetamido-1,3,4-thiadiazol-2-yl)ethyl sulfide (BPTES) were purchased from Sigma-Aldric, Merck KGaA.

Annexin $V$ and dead cell assay. Numbers of live and apoptotic cells were determined using the MUSE Annexin V and Dead Cell kit (Millipore; Merck KGaA, Darmstadt, Germany) according to the manufacturer's instructions. Briefly, cells were seeded at a density of $2.0 \times 10^{5}$ cells/well in six-well plates. After $12 \mathrm{~h}$, cells were incubated with TOFA for $3,6,9$, and $12 \mathrm{~h}$ in a medium without fetal bovine serum. The cells were then washed twice with phosphate-buffered saline (PBS), trypsinized, and mixed well with the MUSE Annexin $\mathrm{V}$ and Dead Cell Assay kit reagents (Millipore, Merck KGaA). Triplicate assays were analyzed using the MUSE cell analyzer.

Palmitate rescue experiment. This assay was performed according to the method of Chun et al. (20). Briefly, four volumes of $4 \%$ fatty acid-free bovine serum albumin in $0.9 \% \mathrm{NaCl}$ were mixed with one volume of $5 \mathrm{mM}$ palmitate (Sigma-Aldrich; Merck KGaA) in ethanol and incubated at $37^{\circ} \mathrm{C}$ for $2 \mathrm{~h}$ to form a $1 \mathrm{mM}$ palmitatebovine serum albumin complex. This complex was added to AsPC1 and BxPC-3 cells in the presence or absence of $60 \mu \mathrm{M}$ TOFA. Each cell was incubated for $12 \mathrm{~h}$ and then assayed according to the annexin $\mathrm{V}$ and dead cell assay as described above.
Caspase-3 activity assay. Cellular caspase-3 activity was measured using Caspase-3/CRP32 Fluorometric Assay kit (Biovision, Mountain View, CA, USA). Briefly, cells were seeded at a density of $2.0 \times 10^{5}$ cells/well in six-well plates. After incubation with TOFA for $3,6,9$, and $12 \mathrm{~h}$, the cells were trypsinized, mixed with cell lysis buffer, and incubated on ice for $10 \mathrm{~min}$. The substrate for caspase3, $N$-acetyl-Asp-Glu-Val-Asp-7-amido-4-trifluoromethylcoumarin, was then added to the lysed cell solution and incubated for $2 \mathrm{~h}$ at $37^{\circ} \mathrm{C}$. Fluorescent intensities of samples were measured at $400 \mathrm{~nm}$ excitation and $505 \mathrm{~nm}$ emission and were analyzed as fluorescent intensity relative to control cells. Assays were conducted in triplicate.

Western blotting. Cells at $60-70 \%$ confluence were washed twice with PBS, and were then lysed with RIPA buffer (ThermoFisher Scientific, San Jose, CA, USA), including a Protease/Phosphatase Inhibitor Cocktail (Cell Signaling Technology Inc., Beverly, MA, USA). Aliquots of protein $(30-40 \mu \mathrm{g})$ were subjected to polyacrylamide gel electrophoresis (12\%), transferred to a polyvinylidene difluoride membrane, and processed for incubation with antibody to ACC1 (Cell Signaling Technology Inc.) for $1 \mathrm{~h}$, followed by anti-rabbit IgG for $1 \mathrm{~h}$. Membranes were reacted with a chemiluminescence reagent (GE Healthcare, Piscataway, NJ, USA). Band density values were normalized to those for glyceraldehyde-3-phosphate dehydrogenase, (GAPDH) (Cell Signaling Technology Inc.).

Proliferation assay. The number of live cells was determined using the MUSE Annexin V and Dead Cell kit as described above. After seeding cells in a six-well plate at a density of $2.0 \times 10^{5}$ cells/well, cells were incubated in medium without fetal bovine serum, EBSS, or PBS without calcium and magnesium ions for the indicated time. The cells were then washed twice with PBS, trypsinized, and mixed well with the MUSE Annexin V and Dead Cell Assay kit reagent. Triplicate assays were analyzed using the MUSE cell analyzer.

Trypan blue dye exclusion test. This test was conducted to study the cell viability by assessing the loss of membrane integrity. The cells were seeded at a density of $2.0 \times 10^{5}$ cells/well in six-well plates. After incubation for $12 \mathrm{~h}$, cells were incubated with each treatment for $24 \mathrm{~h}$. The cells were then washed twice with PBS, trypsinized, and mixed well with trypan blue dye ( $0.4 \%$ solution) at a ratio of 1:1 vol/vol (cell suspension: dye). Live and dead cells were simultaneously counted with an automated cell counter, Countess II (Thermo Fisher). Assays were conducted in triplicate.

Statistical analysis. The overall differences between groups were determined with one-way of analysis of variance (ANOVA).

\section{Results}

Effect of TOFA on induction of apoptosis in pancreatic cancer cells. Previously, we reported that TOFA induced apoptosis in the pancreatic cancer cell line, Miapaca-2 (22). Here, we first investigated whether TOFA had the same effect on other pancreatic cancer cell lines, namely AsPC-1, BxPC-3, and PANC-1 (Figure 1). TOFA significantly increased the annexin $\mathrm{V}$-positive fraction at concentrations more than $60 \mu \mathrm{M}$ in AsPC-1 and more than $40 \mu \mathrm{M}$ in BxPC3 cells after $12 \mathrm{~h}$ (Figure 1A), and its effect was time- 

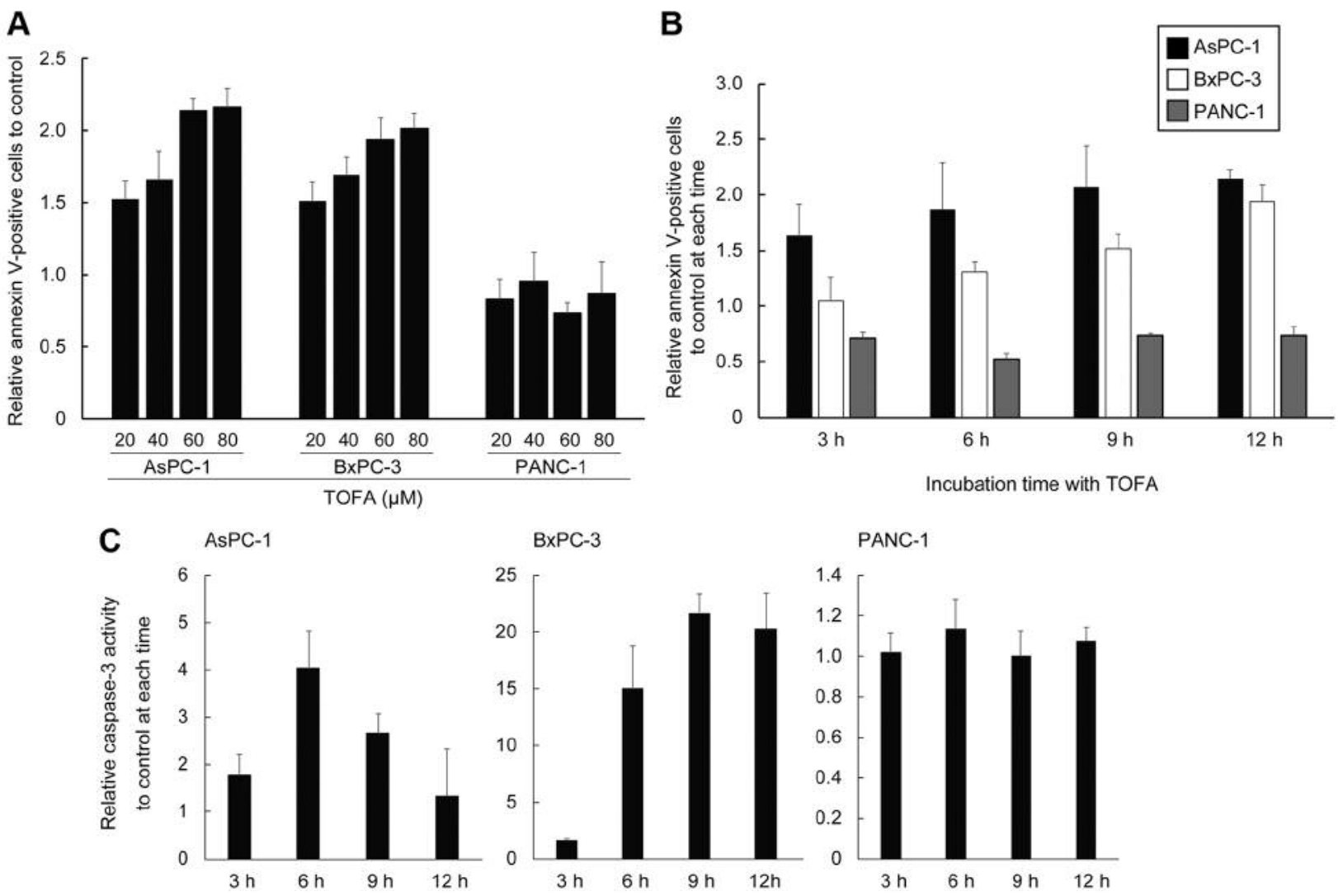

BxPC-3
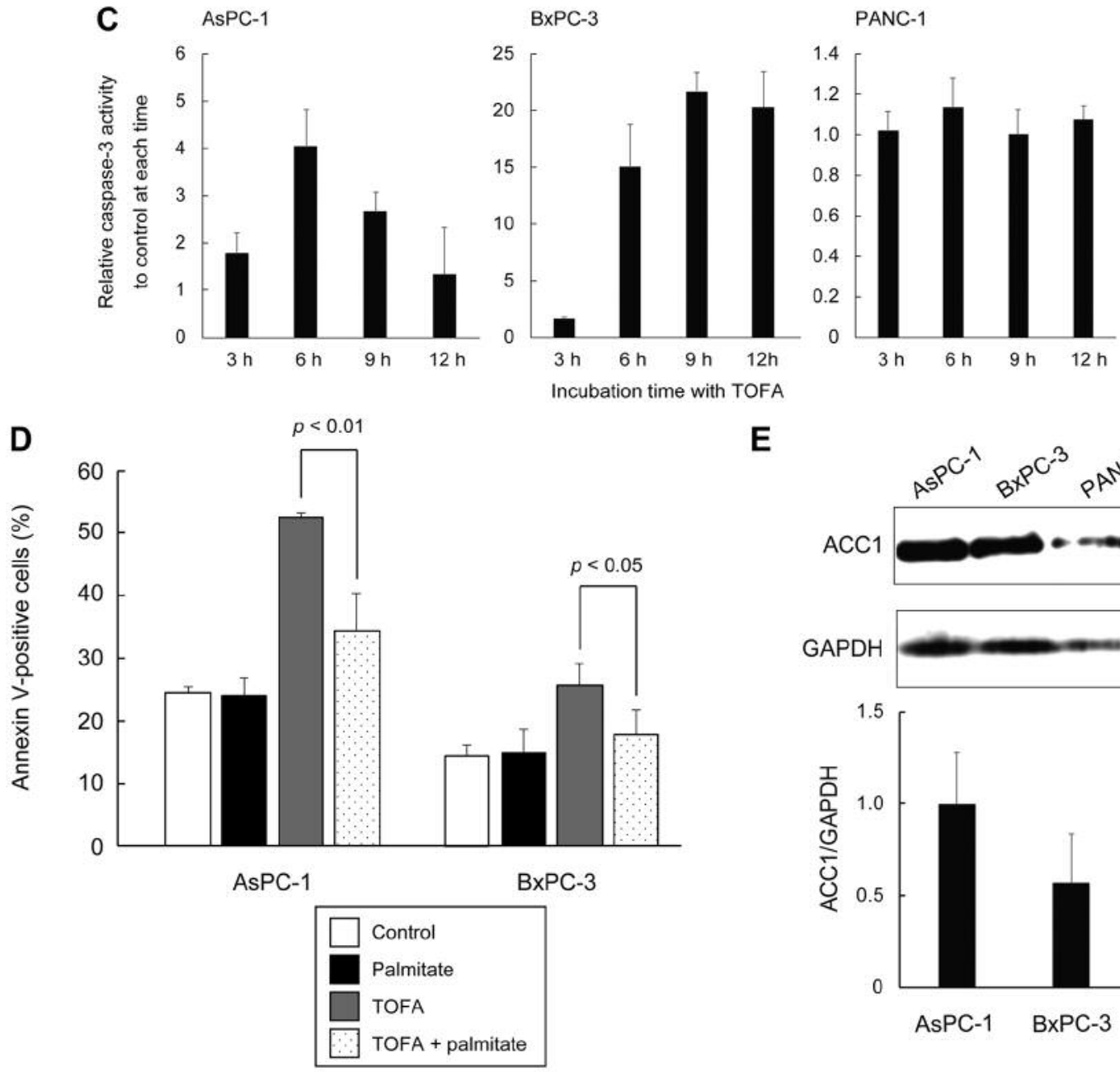

E

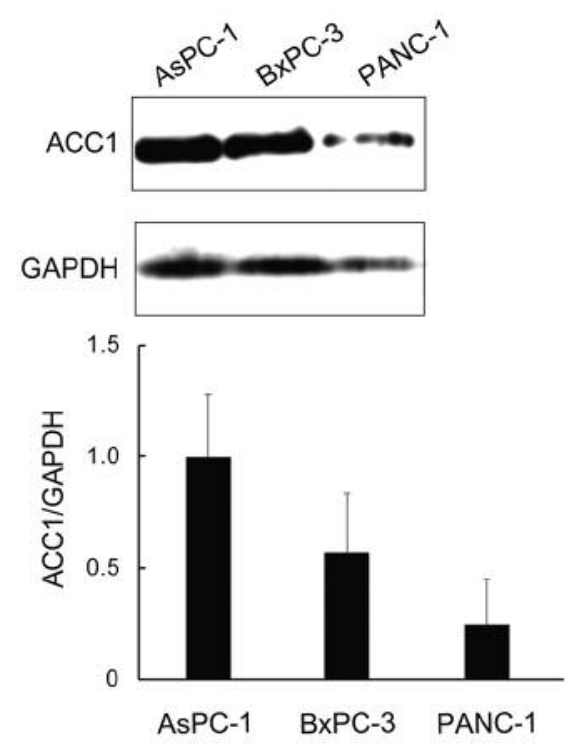

Figure 1. Effect of 5-(tetradecyloxy)-2-furoic acid (TOFA) on induction of apoptosis in pancreatic cancer cells. AsPC-1, BxPC-3, and PANC-1 cells were treated with increasing concentrations of TOFA $(20,40,60$, and $80 \mu \mathrm{M})$ for $12 \mathrm{~h}(\mathrm{~A})$, and with $60 \mu \mathrm{M}$ TOFA for 3-12 $\mathrm{h}(\mathrm{B})$ then annexin $V$ positive cells were measured with the MUSE cell analyzer. C: Caspase-3 activity after treatment with $60 \mu M$ TOFA was measured as described in the Materials and Methods. D: Effect of palmitate on TOFA-induced apoptosis. The cells were treated with $100 \mu \mathrm{M}$ palmitate, $60 \mu \mathrm{M}$ TOFA, and $100 \mu \mathrm{M}$ palmitate plus $60 \mu \mathrm{M}$ TOFA for $12 \mathrm{~h}$. Annexin V-positive cells were measured with the MUSE cell analyzer. E: The expression level of acetyl-CoA carboxylase 1 (ACC1) in each cell line. Glyceraldehyde-3-phosphate dehydrogenase (GAPDH) was assayed to indicate the relative amounts of loaded proteins. The blots shown are representative of three independent experiments. Each bar indicates the mean $\pm S D$ from three independent measurements. 

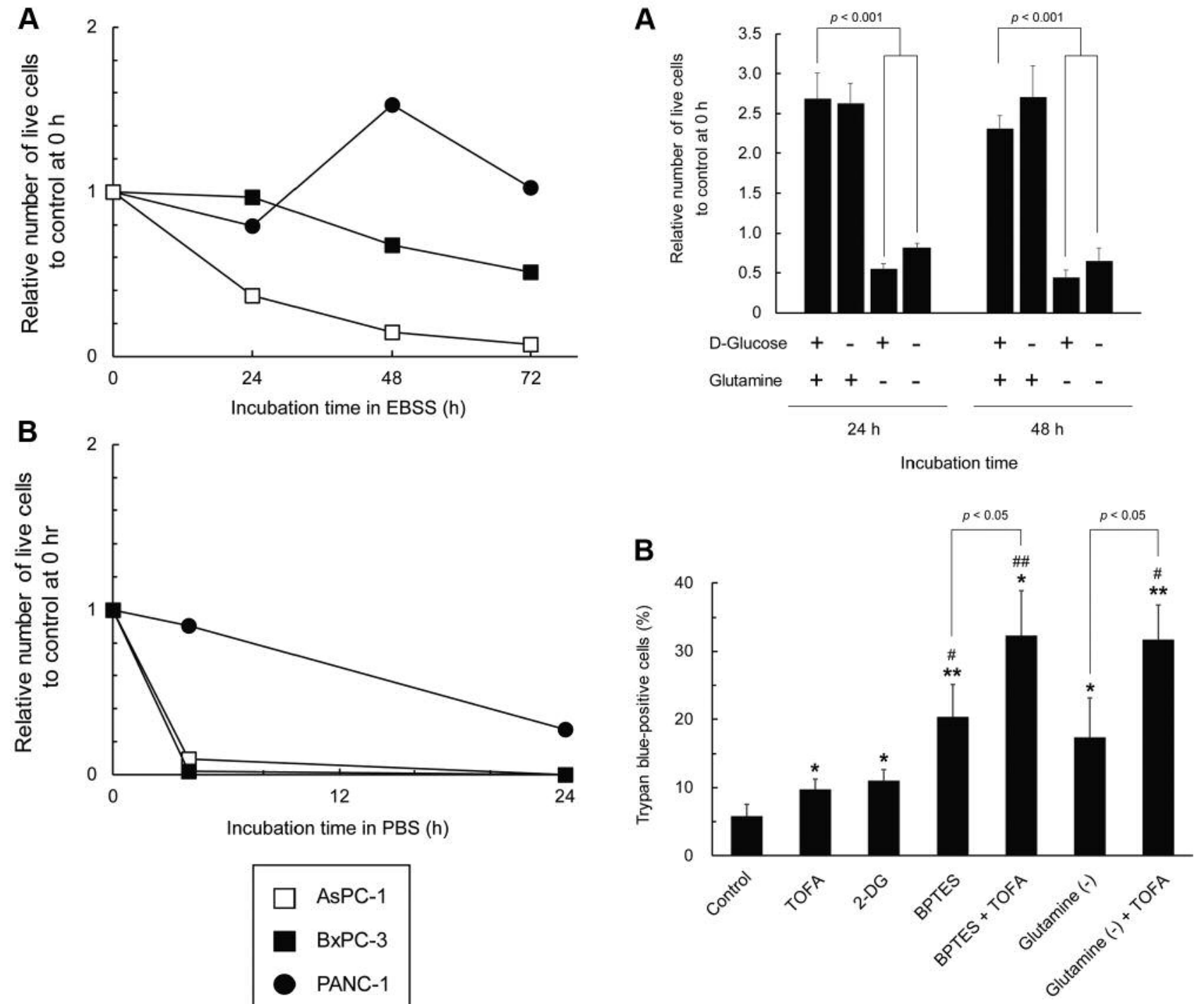

Figure 2. Effect of nutrient starvation in culture medium on proliferation of PANC-1 cells. PANC-1 cells were cultured in Earle's Balanced Salt Solution (EBSS) (A) for 0-72 $h$ and phosphate-buffered saline PBS) (B) for 0-24 $h$. After incubation, cells were analyzed with the MUSE cell analyzer. Each point indicates the mean from three independent measurements.

dependent (Figure 1B). However, we observed no significant effect of TOFA on survival of PANC-1 cells. TOFA also significantly enhanced caspase- 3 activity in AsPC-1 and BxPC-3 cells, but not PANC-1 cells (Figure 1C). To investigate whether this effect of TOFA on AsPC-1 and BxPC- 3 cells was due to a decrease in cellular fatty acids, a palmitate rescue experiment was performed (Figure 1D). Palmitate significantly suppressed the increase in the annexin V-positive fraction induced by TOFA in both AsPC-1 and BxPC-3 cells. To investigate the relationship between the

Figure 3. Effect of glutamine and 2-deoxy-D-glucose (2-DG) on proliferation of PANC-1 cells. A: PANC-1 cells were incubated in a medium without glutamine or 2-DG for 24 or $48 \mathrm{~h}$. Data indicate the mean $\pm S D$ number of live cells relative to the control at $0 \mathrm{~h}$ from three independent measurements. B: PANC-1 cells were treated with 5-(tetradecyloxy)-2-furoic acid (TOFA) $(60 \mu \mathrm{M}), 2-D G(10 \mu M)$, bis-2(5-phenylacetamido-1,3,4-thiadiazol-2-yl)ethyl sulfide (BPTES) (10 $\mu \mathrm{M})$ with or without TOFA, or glutamine-free medium with or without TOFA for $24 \mathrm{~h}$. Dead cells are presented as the fraction of trypan blue-positive cells to total cells. Each bar indicates the mean $\pm S D$ from three independent measurements. Significantly different vs. control at $* p<0.05$ and ${ }^{* *} p<0.01 ; v s$. TOFA at ${ }^{\#} p<0.05,{ }^{\# \#} p<0.01$.

effect of TOFA and expression levels of ACC 1 in these cell lines, we measured the expression levels of ACC1 (ACC $\alpha$ ) in AsPC-1, BxPC-3, and PANC-1 cells with western blotting (Figure 1E). The expression level of ACC1 in PANC-1 cells was lower than the levels in AsPC-1 and BxPC-3 cells. 

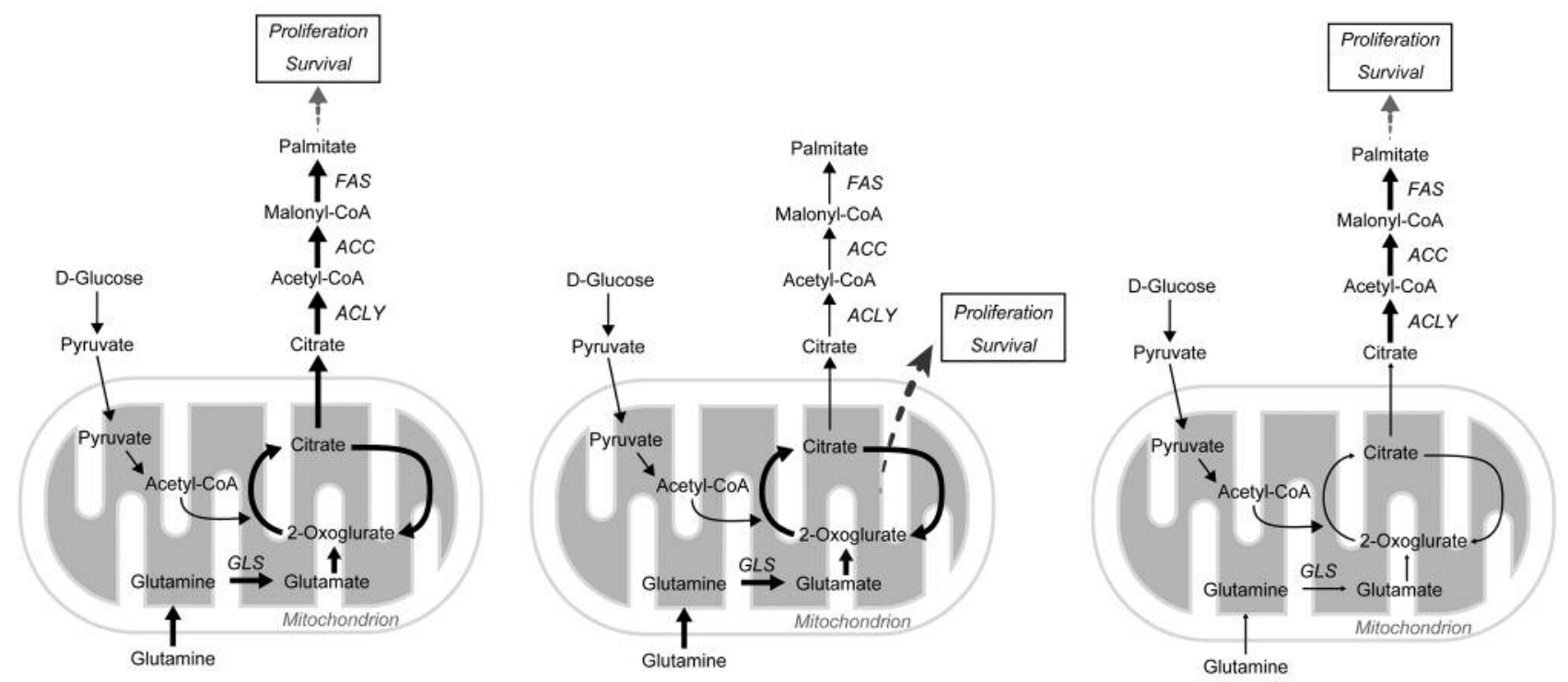

Figure 4. Proposed mechanism of survival and proliferation of pancreatic cancer cells. AsPC-1 and BxPC-3 cells are dependent on fatty acid synthesis and glutamine for survival (A). On the other hand, nutrient starvation-resistant cancer cells, such as PANC-1 cells, are dependent on glutamine $(B)$. Glutamine deprivation changes the intracellular metabolism of PANC-1 cells, which then become dependent on fatty acid synthesis for survival and proliferation $(C)$.

Proliferation of PANC-1 cells in nutrient starvation medium. The above results indicated that PANC-1 cells can survive even in an environment with a low amount of cellular fatty acids. Therefore, we investigated the proliferation of PANC-1 cells in several types of nutrient starvation media. Figure $2 \mathrm{~A}$ shows the relative number of live AsPC-1, BxPC-3, and PANC-1 cells cultured in EBSS, a starvation medium. PANC1 showed proliferation up to $48 \mathrm{~h}$, even in EBSS. Surprisingly, PANC-1 cells could partly survive even in PBS without calcium and magnesium, at least up to $24 \mathrm{~h}$ (Figure 2B).

Effect of glutamine and 2-deoxy-D-glucose on proliferation of PANC-1 cells. The above results indicated that PANC-1 cells are tolerant to deprivation of not only fatty acids, but also other nutrients. To identify the factor involved in this tolerance, we investigated the effects of 2-deoxy-D-glucose and glutamine on the proliferation of PANC-1 cells. Interestingly, glutamine deprivation of the medium drastically suppressed the number of PANC- 1 cells after 24 and $48 \mathrm{~h}$, but glucose deprivation had a lesser effect (Figure 3A). Glutamine is mainly supplied via two pathways, glutaminolysis and nucleotide synthesis. To elucidate which pathway mainly functions for glutamine use in PANC-1 cells, we investigated the effect of BPTES, an inhibitor of GLS. We found that BPTES induced cell death to a similar extent as glutamine deprivation. Furthermore, both BPTES and glutamine deprivation synergistically enhanced the effect of TOFA (Figure 3B).

\section{Discussion}

In the current study, we investigated the possibility that inhibition of fatty acid synthesis may be a new therapeutic strategy for treatment of pancreatic cancer. Inhibition of fatty acid synthesis by TOFA induced apoptosis in AsPC-1 and BxPC-3 cells. Addition of palmitate rescued the cells from apoptosis, suggesting that apoptosis is due to the decrease in fatty acids. On the other hand, TOFA did not induce apoptosis of PANC-1 cells. Fatty acids are used not only for cellular energy but also as materials in structures such as lipid membranes. We found that TOFA suppressed proliferation of PANC-1 cells (data not shown). This result implies that PANC-1 cells do not require, or only minimally require, fatty acids as a source of energy. We initially expected that the minimal effect of TOFA on PANC-1 cells was due to high expression of ACC1 compared to other cell lines. However, the expression level of ACC1 in PANC-1 cells was lower than that in AsPC-1 and BxPC-1 cells. Such a low level of ACC1 expression in PANC-1 cells may indicate that PANC-1 cells are not dependent, or only minimally dependent, on de novo fatty acid synthesis for survival. Little difference was seen in the doubling time of these cell lines at least up to $24 \mathrm{~h}$, suggesting that the difference in the effect of TOFA on these cell lines is not due to the rate of cell proliferation (data not shown). Moreover, we found that $\mathrm{C} 75$ and cerulenin, inhibitors of FAS, induced 
apoptosis in PANC-1 cells (data not shown). This may be due to toxicity of accumulated malonyl-CoA (21).

The number of PANC-1 cells still increased after incubation for up to $48 \mathrm{~h}$ in EBSS. This result indicates that PANC-1 cells have the potential to survive under conditions of reduced nutrients, including lack of fatty acids. Surprisingly, PANC-1 cells also survived in PBS without calcium and magnesium ions. In addition, PANC-1 cells were partly attached to the bottom of the well, even though divalent cations such as calcium and magnesium ions are important factors for cell adhesion. Therefore, PANC-1 cells may also have the ability to survive in an environment without divalent cations, perhaps for short times. Although EBSS does not have glutamine, PANC-1 cells survived in EBSS better than in DMEM without glutamine. This may be because their cellular metabolism in EBSS changed to adapt to the new environment of nutrient starvation, and deprivation of glutamine alone led to drastic suppression of proliferation of PANC-1 cells. We observed that glutamine deprivation also suppressed the proliferation of AsPC-1 and BxPC-3 cells. This effect is thought to be related to glutaminolysis or the tricarboxylic acid cycle, but not nucleotide synthesis, because BPTES induced a similar level of cell death as glutamine deprivation. Moreover, BPTES and glutamine deprivation synergistically enhanced the effect of TOFA on PANC-1 cells, even though treatment with only TOFA did not have a lesser effect. This may be because suppression of glutaminolysis leads to suppression of ACC expression, followed by a decrease in fatty acids or an increase in dependence on fatty acids instead of glutamine, even though PANC-1 cells are usually not dependent on fatty acids for survival. Previous studies have reported that glutamate and citrate positively regulate the expression of $\operatorname{ACC}(25,26)$. These findings suggest that glutamine deprivation may cause a decrease in glutamate and citrate in PANC-1 cells, and then this decrease suppresses ACC1 expression in PANC-1 cells even more, resulting in fatty acid starvation. On the other hand, inhibition of glycolysis by glucose deprivation or 2-deoxy-D-glucose had little effect on PANC-1 cell survival, even though glycolysis is also an important pathway for production of acetyl-CoA. This may be because acetyl-CoA is supplied from cytosol citrate through ATP citrate lyase activity. Decrease in citrate production by inhibition of glutaminolysis may result in a greater decrease in fatty acids in PANC-1 cells $(12,13,27,28)$. Therefore, blocking the reaction from glutamine to glutamate in addition to inhibition of fatty acid synthesis may be a novel treatment strategy for pancreatic cancer, which is especially tolerant to nutrient starvation.

\section{Acknowledgements}

This work was supported, in part, by a Grant-in-Aid for Scientific Research (C) Grant Number 17K08429 from the Japan Society for the Promotion of Science (JSPS), Japan.

\section{References}

1 Siegel RL, Miller KD and Jemal A: Cancer statistics, 2017. CA Cancer J Clin 67(1): 7-30, 2017.

2 Saif MW: Pancreatic neoplasm in 2011: An update. J Pancreas 12(4): 316-321, 2011.

3 Hori M, Matsuda T, Shibata A, Katanoda K, Sobue T and Nishimoto H: Cancer incidence and incidence rates in Japan in 2009: A study of 32 population-based cancer registries for the Monitoring of Cancer Incidence in Japan (MCIJ) project. Jpn J Clin Oncol 45(9): 884-891, 2015.

4 Moore MJ, Goldstein D, Hamm J, Figer A, Hecht JR, Gallinger S, Au HJ, Murawa P, Walde D, Wolff RA, Campos D, Lim R, Ding K, Clark G, Voskoglou-Nomikos T, Ptasynski M and Parulekar W: Erlotinib plus gemcitabine compared with gemcitabine alone in patients with advanced pancreatic cancer: A phase III trial of the National Cancer Institute of Canada Clinical Trials Group. J Clin Oncol 25(15): 1960-1966, 2007.

5 Conroy T, Desseigne F, Ychou M, Bouche O, Guimbaud R, Becouarn Y, Adenis A, Raoul JL, Gourgou-Bourgade S, de la Fouchardiere C, Bennouna J, Bachet JB, Khemissa-Akouz F, Pere-Verge D, Delbaldo C, Assenat E, Chauffert B, Michel P, Montoto-Grillot $\mathrm{C}$ and Ducreux $\mathrm{M}$ : Folfirinox versus gemcitabine for metastatic pancreatic cancer. N Engl J Med 364(19): 1817-1825, 2011.

6 Von Hoff DD, Ervin T, Arena FP, Chiorean EG, Infante J, Moore M, Seay T, Tjulandin SA, Ma WW, Saleh MN, Harris M, Reni M, Dowden S, Laheru D, Bahary N, Ramanathan RK, Tabernero J, Hidalgo M, Goldstein D, Van Cutsem E, Wei X, Iglesias J and Renschler MF: Increased survival in pancreatic cancer with nabpaclitaxel plus gemcitabine. N Engl J Med 369(18): 1691-1703, 2013.

7 Kuhajda FP: Fatty-acid synthase and human cancer: New perspectives on its role in tumor biology. Nutrition 16(3): 202208, 2000.

8 Milgraum LZ, Witters LA, Pasternack GR and Kuhajda FP: Enzymes of the fatty acid synthesis pathway are highly expressed in in situ breast carcinoma. Clin Cancer Res 3(11): 2115-2120, 1997.

9 Tong L: Acetyl-coenzyme a carboxylase: Crucial metabolic enzyme and attractive target for drug discovery. Cell Mol Life Sci 62(16): 1784-1803, 2005.

10 Chakravarty B, Gu Z, Chirala SS, Wakil SJ and Quiocho FA: Human fatty acid synthase: Structure and substrate selectivity of the thioesterase domain. Proc Natl Acad Sci USA 101(44): 15567-15572, 2004.

11 Chirala SS and Wakil SJ: Structure and function of animal fatty acid synthase. Lipids 39(11): 1045-1053, 2004.

12 Hatzivassiliou G, Zhao F, Bauer DE, Andreadis C, Shaw AN, Dhanak D, Hingorani SR, Tuveson DA and Thompson CB: ATP citrate lyase inhibition can suppress tumor cell growth. Cancer Cell 8(4): 311-321, 2005.

13 Bauer DE, Hatzivassiliou G, Zhao F, Andreadis C and Thompson CB: ATP citrate lyase is an important component of cell growth and transformation. Oncogene 24(41): 6314-6322, 2005.

14 Swinnen JV, Brusselmans K and Verhoeven G: Increased lipogenesis in cancer cells: New players, novel targets. Curr Opin Clin Nutr Metab Care 9(4): 358-365, 2006.

15 Brusselmans K, De Schrijver E, Verhoeven G and Swinnen JV: Rna interference-mediated silencing of the acetyl-CoA- 
carboxylase-alpha gene induces growth inhibition and apoptosis of prostate cancer cells. Cancer Res 65(15): 6719-6725, 2005.

16 Svensson RU, Parker SJ, Eichner LJ, Kolar MJ, Wallace M, Brun SN, Lombardo PS, Van Nostrand JL, Hutchins A, Vera L, Gerken L, Greenwood J, Bhat S, Harriman G, Westlin WF, Harwood HJ, Jr., Saghatelian A, Kapeller R, Metallo CM and Shaw RJ: Inhibition of acetyl-CoA-carboxylase suppresses fatty acid synthesis and tumor growth of non-small-cell lung cancer in preclinical models. Nat Med 22(10): 1108-1119, 2016.

17 Chajes V, Cambot M, Moreau K, Lenoir GM and Joulin V: Acetyl-coa carboxylase alpha is essential to breast cancer cell survival. Cancer Res 66(10): 5287-5294, 2006.

18 Beckers A, Organe S, Timmermans L, Scheys K, Peeters A, Brusselmans K, Verhoeven G and Swinnen JV: Chemical inhibition of acetyl-CoA-carboxylase induces growth arrest and cytotoxicity selectively in cancer cells. Cancer Res 67(17): 8180-8187, 2007.

19 Zhou W, Simpson PJ, McFadden JM, Townsend CA, Medghalchi SM, Vadlamudi A, Pinn ML, Ronnett GV and Kuhajda FP: Fatty acid synthase inhibition triggers apoptosis during $\mathrm{S}$ phase in human cancer cells. Cancer Res 63(21): 7330-7337, 2003.

20 Wang C, Xu C, Sun M, Luo D, Liao DF and Cao D: AcetylCoA-carboxylase-alpha inhibitor TOFA induces human cancer cell apoptosis. Biochem Biophys Res Commun 385(3): 302-306, 2009.

21 Pizer ES, Thupari J, Han WF, Pinn ML, Chrest FJ, Frehywot GL, Townsend CA and Kuhajda FP: Malonyl-coenzyme-A is a potential mediator of cytotoxicity induced by fatty-acid synthase inhibition in human breast cancer cells and xenografts. Cancer Res 60(2): 213-218, 2000.

22 Nishi K, Suzuki K, Sawamoto J, Tokizawa Y, Iwase Y, Yumita $\mathrm{N}$ and Ikeda $\mathrm{T}$ : Inhibition of fatty acid synthesis induces apoptosis of human pancreatic cancer cells. Anticancer Res 36(9): 4655-4660, 2016.
23 Izuishi K, Kato K, Ogura T, Kinoshita $\mathrm{T}$ and Esumi $\mathrm{H}$ : Remarkable tolerance of tumor cells to nutrient deprivation: Possible new biochemical target for cancer therapy. Cancer Res 60(21): 6201-6207, 2000.

24 Maddocks ODK, Athineos D, Cheung EC, Lee P, Zhang T, van den Broek NJF, Mackay GM, Labuschagne CF, Gay D, Kruiswijk F, Blagih J, Vincent DF, Campbell KJ, Ceteci F, Sansom OJ, Blyth K and Vousden KH: Modulating the therapeutic response of tumours to dietary serine and glycine starvation. Nature 544(7650): 372-376, 2017.

25 Baquet A, Gaussin V, Bollen M, Stalmans W and Hue L: Mechanism of activation of liver acetyl-CoA-carboxylase by cell swelling. Eur J Biochem 217(3): 1083-1089, 1993.

26 Wakil SJ and Abu-Elheiga LA: Fatty acid metabolism: Target for metabolic syndrome. J Lipid Res 50(Suppl): S138-143, 2009.

27 Currie E, Schulze A, Zechner R, Walther TC and Farese RV Jr.: Cellular fatty acid metabolism and cancer. Cell Metab 18(2): 153-161, 2013.

28 Migita T, Narita T, Nomura K, Miyagi E, Inazuka F, Matsuura M, Ushijima M, Mashima T, Seimiya H, Satoh Y, Okumura S, Nakagawa $\mathrm{K}$ and Ishikawa $\mathrm{Y}$ : Atp citrate lyase: Activation and therapeutic implications in non-small cell lung cancer. Cancer Res 68(20): 8547-8554, 2008.
Received November 6, 2018

Revised November 15, 2018

Accepted November 19, 2018 